\title{
Dispersal of the bryozoan Bugula neritina and effects of adults on newly metamorphosed juveniles
}

\author{
Michael J. Keough \\ Department of Zoology, University of Melbourne, Parkville, Victoria 3052, Australia
}

\begin{abstract}
In southern California, colonies of the arborescent bryozoan Bugula neritina have a strongly clumped spatial distribution. Small colonies are generally $<4 \mathrm{~cm}$ from other small colonies, and within 10 to $15 \mathrm{~cm}$ of large, reproductive colonies. In the laboratory, larvae are capable of swimming for $2 \mathrm{~d}$ in the absence of settlement cues. The actual duration of the larval period is reduced to $<2 \mathrm{~h}$ when substrata are present, and larvae spend most of their brief presettlement period examining the substratum. Duration of the larval period in the absence of suitable substrata does not vary among larvae from different parent colonies or with temperature. Larvae do not respond to the presence of previously settled juveniles, so the proximity of juveniles to existing colonies most likely represents limited dispersal of larvae in the presence of abundant field settlement cues. To assess the effects of adults on young bryozoans, day-old juveniles were transplanted into the field with and without adult colonies present. There were no consistent effects of adult colonies on either growth or survival of juveniles. Survivorship varied among 3 experimental sites, but was unaffected by the presence of adults. High mortality of adult colonies was accompanied by high juvenile mortality. Growth rates of juveniles were affected significantly by adults, but in no consistent way. At one site, juvenile growth was higher beneath a canopy, at the second, growth was lower, while there was no difference at the third site.
\end{abstract}

\section{INTRODUCTION}

Marine animals vary greatly in their life history characteristics, including dispersal ability. Although most attention has been paid to widely-dispersing intertidal animals, such as barnacles and mussels, the dispersive phase of benthic species ranges in length from months (Scheltema 1971) to minutes, and may not even involve a swimming planktonic stage (Thorson 1950, Bergquist 1981, Gerrodette 1981). Many of these latter species presumably have very restricted dispersal (Keough 1989), but the consequences of restricted dispersal have until recently received little attention in marine habitats (Gerrodette 1981, Fadlallah \& Pearse 1982, Burton 1983, Sebens 1983, Levin 1984, Ayre 1985, Olson 1985, Young 1986, Davis 1987, Keough \& Chernoff 1987). In contrast to marine animals, the consequences of limited dispersal have received more attention in terrestrial plants (see Harper 1977 for review). Possible results include local genetic differentiation (Turkington \& Harper 1979) and patchy demography (Fowler \& Antonovics 1981). One important consequence may be a close spatial association of juveniles with conspecific adults. If a local population is to persist, juveniles must be able to live in the physical environment in the proximity of adults. This is especally true for arborescent organisms such as plants and some sessile animals, which depend on access to light or the water column. The reverse pattern, in which juveniles survive poorly near conspecific adults, was suggested as a mechanism maintaining tree diversity in forests (Janzen 1970, Connell 1971, 1978). Interactions between established adults and recruits are poorly known for most marine organisms.

This paper describes the spatial distribution and some of its consequences in the warm temperate bryozoan Bugula neritina (L.) in a rocky subtidal habitat of southern California, USA. B. neritina has a life history that makes intraspecific interactions likely; it is a suspensionfeeding, colonial animal, with an upright bushy growth form and larvae that are brooded singly in large ovicells. Larvae do not feed, are thought to be short-lived and presumably do not disperse far. Here, I describe the distribution of colonies of various sizes in the field, 
quantify larval swimming times under various laboratory conditions, and examine experimentally the effects of resident adults on juvenile growth and survival.

\section{METHODS}

Bugula neritina colonies are conspicuous members of many fouling communities, but substantial populations live on natural substrata in, e.g., California and Florida (Winston 1982, Keough 1986, Keough \& Chernoff 1987). The populations studied here live on subtidal rock surfaces near the Catalina Marine Science Center, Santa Catalina Island, near Los Angeles, California. Data were collected from 3 localities, all at 8 to $12 \mathrm{~m}$ depth. 'Intake Pipes' is $100 \mathrm{~m} \mathrm{E}$ of the intakes for the seawater system of the laboratory, with a canopy of Giant Kelp Macrocystis pyrifera (L.) C.Ag. The other 2 sites, Bird Rock (for descriptions see Vance 1978) and Isthmus Reef (see Keough \& Downes 1982, 1986, Keough 1984) presently lack macroalgal canopies, although extensive Macrocystis populations occurred recently at both sites.

At each site, I estimated the abundance of Bugula neritina with a series of randomly placed $1 \mathrm{~m}^{2}$ quadrats, in which I recorded the size and position of each $B$. neritina colony. In addition to these measurements, I mapped all colonies within a series of $2 \mathrm{~m} \times 15 \mathrm{~m}$ belt transects. Two divers crawled over each transect and measured the size and coordinates of all B. neritina. A single transect at Intake Pipes was sufficient to give large sample sizes, and I used 3 at Bird Rock and 6 at Isthmus Reef. The transect data were analysed using the normally distributed nearest-neighbour statistic of Hopkins \& Skellam (1954). Colonies were divided into 3 size classes: small juveniles (up to 5 bifurcations), large juveniles ( 6 to 12 bifurcations), and potentially reproductive adults (at least 15 bifurcations). I determined the distribution of each size class relative to nearest neighbours of the same size class, and to neighbours that were mature colonies, using the nearest-neighbour method of Hopkins \& Skellam (1954), with the slight modification described in an earlier paper (Keough 1984).

The size and/or growth of large, arborescent colonies is difficult to measure accurately, but for Bugula neritina populations in Florida, I have developed a means of estimating colony size or growth (Keough \& Chernoff 1987). Zooids are paired along the branches of $B$. neritina colonies. The ancestrula begins to reproduce clonally, and the small colony then bifurcates. Each of these branches grows and bifurcates, and so on. The number of zooids can then be estimated in situ by counting the number of times that a colony has bifurcated (Keough \& Chemoff 1987). To test whether the same method would be accurate in California, I collected a series of colonies of a range of sizes, and counted the number of branches at each level of the colony and the number of zooids between each pair of bifurcations.

To confirm that the large colonies were potential parents, I examined a large number of randomly chosen colonies at Intake Pipes during the reproductive season, measuring for each colony its size and the presence or absence of embryos.

It is difficult to observe dispersal in the field, because Bugula neritina larvae are dark colored and difficult to see. Successful field observations of dispersal have been made only using larger tunicate larvae (van Duyl et al. 1981, Olson 1985, Young 1986, Davis 1987) and coral planulae (Resing \& Best 1989), and even then it was not possible to follow larvae that did not settle within $30 \mathrm{~min}$. The laboratory experiments were designed to examine the behavior of larvae under 2 extreme conditions. Larvae without suitable substrata for settlement provided estimates of potential maximum swimming times, and larvae provided with substrata allowed estimation of settlement times when substrata could be located immediately.

Large colonies were collected from Intake Pipes and placed in the dark for $24 \mathrm{~h}$. When exposed to bright light after this time they released larvae. Settlement arenas were $2.5 \mathrm{~cm}$ diameter culture dishes. Settlement substrata were pieces of mussel (Mytilus californianus Conrad) shell that had been collected from Bird Rock. M. californianus shells are abundant at many localities around the laboratory, and Bugula neritina colonies use these shells as substrata. After larvae had been added to dishes, they were placed in dim, diffuse light and examined at periodic intervals. After successful attachment, the larva begins to elongate, prior to forming the ancestrula. A larva was considered to have settled when elongation began.

Expt I tested the effects of settlement cues on swimming time and examined variation in behavior among larvae from different colonies. I used 3 colonies (labelled 5,6 and 8 ; larvae from these colonies were also part of another, larger experiment), with one larva per dish. To eliminate effects of any physical heterogeneity in the laboratory, the experiment was done using five $6 \times 6$ arrays of culture dishes, with colonies and treatments arranged in Latin Squares. The replicates were examined in the order in which they were established. The experiment was done at ambient seawater temperature $\left(21^{\circ} \mathrm{C}\right)$.

Expt II tested the effects of temperature on swimming time. Because Bugula neritina colonies reproduce throughout the year at Santa Catalina Island, larvae experience a range of temperatures, and dependence of swimming time might produce seasonally-varying potential dispersal. Larvae were added to dishes con- 
taining settlement substrata at 3 different temperatures $\left(15,21\right.$ and $\left.28^{\circ} \mathrm{C}\right)$, and kept in constant-temperature cabinets.

Interactions between adults and juveniles. This experiment contrasted the growth and mortality of juveniles in the presence and absence of an adult canopy in the field. The 2 treatments were produced by adding adults to half of a group of substrata with newly settled juveniles. Experimental substrata were unglazed clay tiles 6 to $7 \mathrm{~cm}$ on a side. They had been immersed in running seawater for $>7 \mathrm{~d}$ to allow development of a diatomaceous or bacterial film, which enhances Bugula neritina settlement (Mihm et al. 1981). Larvae were obtained as described above, and allowed to settle on the experimental substrata. Settlement was restricted to an area ca $2 \mathrm{~cm}$ in diameter in the centre of each substratum by standing a $5 \mathrm{~cm}$ section of $2 \mathrm{~cm}$ diameter PVC pipe on each tile and pipetting larvae into this pipe. The settled individuals were allowed to metamorphose for $1 \mathrm{~d}$. Where necessary, I reduced the number of larvae to 5 .

Canopies were added to randomly assigned tiles by drilling a $5 \mathrm{~mm}$ diameter, $7 \mathrm{~mm}$ deep hole near the centre of the tile. I added a large Bugula neritina colony to each tile in the canopy treatment by wrapping the base of the colony in foam rubber and then pushing it into the drill-hole, where it was held firm by the expansion of the rubber. The tiles were then transported to the Intake Pipes study site in trays of seawater, and there attached to 3 wire grids that had been bolted flush against the rock surfaces at a depth of 10 to $12 \mathrm{~m}$. I used 49 canopy tiles and 52 no-canopy tiles, with a total of 408 larvae, divided approximately equally between the 2 treatments. After $3 \mathrm{~d}$ I checked the condition of the canopies, and after 4 and $18 \mathrm{wk}$ I counted the surviving juveniles and measured their sizes in situ.

\section{RESULTS}

\section{Field observations}

Colonies were more abundant at Intake Pipes than at the other 2 sites. Colonies were uncommon at Isthmus Reef ( 0.5 colonies $\mathrm{m}^{-2}, \mathrm{SD}=1.9, \mathrm{n}=80$ quadrats) and Bird Rock ( 2.00 colonies $\mathrm{m}^{-2}, \mathrm{SD}=3.5, \mathrm{n}=25$ ), but were extremely common at Intake Pipes ( 16.3 colonies $\mathrm{m}^{-2}, \mathrm{SD}$ $=21.5, \mathrm{n}=31$; ANOVA using square-root-transformed data, $F_{2,133}=43.4, p<0.001$; SNK [Student-NewmanKeuls] procedure indicated that Isthmus Reef and Bird Rock densities were not significantly different).

The size-frequency distributions of colonies at the 3 sites differed significantly (log-likelihood ratio analysis of 3 sites $\times 12$ size classes contingency table, $\mathrm{G}=$ 44.52 , $\mathrm{df}=22, \mathrm{p}<0.01$ ). In pairwise tests, there was no significant difference between Isthmus Reef and Intake Pipes $(\mathrm{G}=7.94 \mathrm{df}=11, \mathrm{p}>0.05)$, but both of these sites differed significantly from Bird Rock (Isthmus Reef, $\mathrm{G}=25.0$, $\mathrm{df}=10, \mathrm{p}<0.01$; Intake Pipes, $\mathrm{G}=$ 40.1, df $=10, \mathrm{p}<0.01$ ).

Bugula neritina colonies had a markedly clumped distribution at all 3 sites, whether measured by the comparison of the number of Bugula per quadrat to the expectations generated by a Poisson distribution (goodness-of-fit tests, Intake Pipes $G=89, \mathrm{df}=1$; Isthmus Reef $\mathrm{G}=59, \mathrm{df}=2$; Bird Rock $\mathrm{G}=63, \mathrm{df}=2$, all $p \ll 0.001$ ) or by nearest-neighbour analysis (Fig. 1; Table 1). At Intake Pipes, colonies of a given size class were significantly closer than expected by chance to mature colonies, with mean distances of the order of 8 to $10 \mathrm{~cm}$ (Fig. 1). They were even closer to colonies of the same size class, with mean distances to first nearest neighbour of $1 \mathrm{~cm}$ for the smallest size class (Fig. 1). In every case the distribution was significantly aggregated, and most of the colonies that had no close neighbours were close to the edges of the belt transects. These colonies most likely had neighbours just
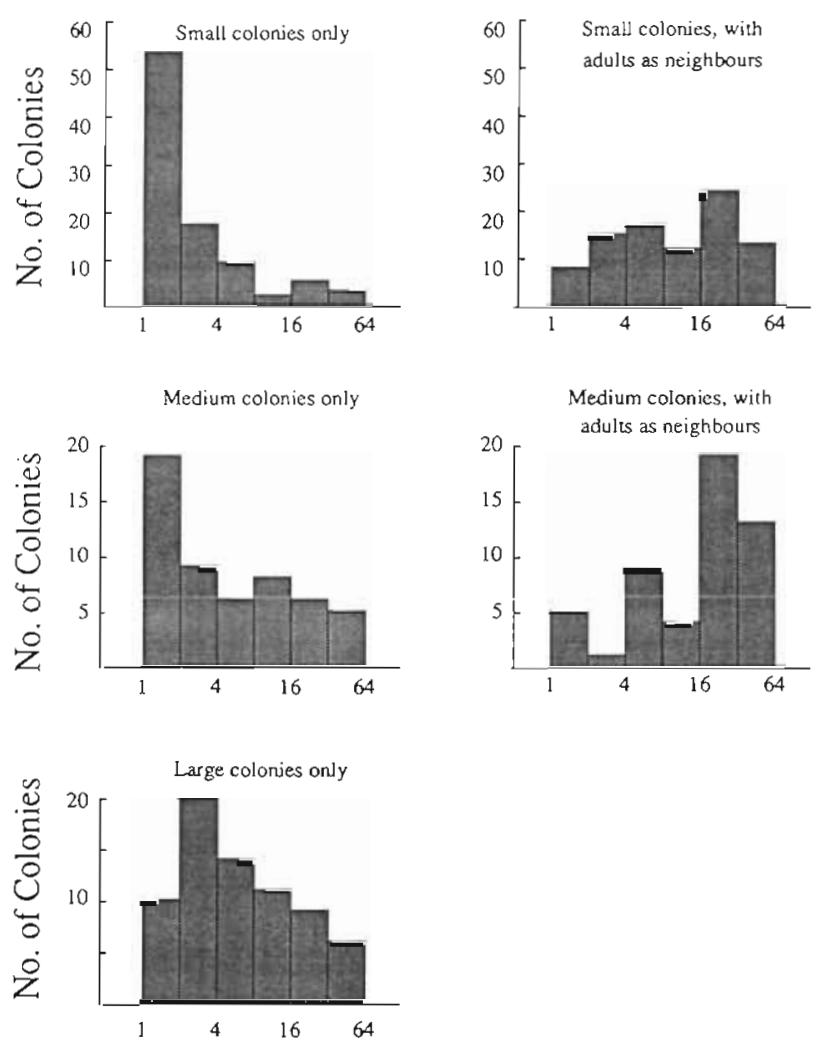

Distance to Nearest Neighbour $(\mathrm{cm})$

Fig. 1. Bugula neritina. Histograms of nearest neighbour distances for colonies in 3 size groups at Intake Pipes. For smaller colonies, the distribution of distances to the nearest neighbour of the same size and to a large neighbour are shown 
beyond the transect perimeters. The nearest-neighbour method assumes that individuals are points occupying no area. I made no correction for the area occupied by colonies (Simberloff's [1979] 'disk' correction), because colonies were found with their basal areas in contact, so it is the area of the holdfast, rather than the area of the 'canopy' that is crucial. In any event, failure to adjust for the size of individuals biases the outcome towards overdispersion (Simberloff 1979).

\section{Morphology}

The number of bifurcations was a good indicator of the number of zooids in a colony (Fig. 2). There were

Table 1. Bugula nentina. Nearest-neighbour analyses of distributions. The table shows the value of the normalized Hopkins-Skellam statistic, together with the mean distance to first nearest neighbour. The probability shown is that associated with a test of the null hypothesis that the distribution is random $(X=0.5)$

\begin{tabular}{|c|c|c|c|}
\hline Comparison & $\begin{array}{l}\text { Distance } \\
\text { to neigh- } \\
\text { bour } \\
\text { (mean, cm) }\end{array}$ & $\begin{array}{l}\text { Hopkins- } \\
\text { Skellam } \\
\text { statistic } \\
\text { (X) }\end{array}$ & $p$ \\
\hline $\begin{array}{l}\text { Intake Pipes } \\
\text { Small colonies } \\
(N=89)\end{array}$ & 4.4 & 0.999 & $<0.0001$ \\
\hline $\begin{array}{l}\text { Small colonies, relative } \\
\text { to mature colonies }\end{array}$ & 19.1 & 0.969 & $<0.0001$ \\
\hline $\begin{array}{l}\text { Medium colonies } \\
(N=58)\end{array}$ & 16.1 & 0.982 & $<0.0001$ \\
\hline $\begin{array}{l}\text { Medium colonies, rela- } \\
\text { tive to adult colonies }\end{array}$ & 27.2 & 0.956 & $<0.0001$ \\
\hline $\begin{array}{l}\text { Adult colonies } \\
(\mathrm{N}=73)\end{array}$ & 10.5 & 0.991 & $<0.0001$ \\
\hline $\begin{array}{l}\text { Bird Rock } \\
\text { Small colonies } \\
(\mathrm{N}=24)\end{array}$ & 26.8 & 0.620 & 0.046 \\
\hline $\begin{array}{l}\text { Small colonies, relative } \\
\text { to mature colonies }\end{array}$ & 110.3 & 0.109 & $<0.001$ \\
\hline $\begin{array}{l}\text { Large colonies } \\
(\mathrm{N}=5)\end{array}$ & 123.2 & 0.666 & 0.48 \\
\hline $\begin{array}{l}\text { Isthmus Reef } \\
\text { Small colonies } \\
(\mathrm{N}=26)\end{array}$ & 42.1 & 0.434 & 0.169 \\
\hline $\begin{array}{l}\text { Small colonies, relative } \\
\text { to mature colonies }\end{array}$ & 95.8 & 0.8 & 0.001 \\
\hline $\begin{array}{l}\text { Medium colonies } \\
(N=17)\end{array}$ & 30.7 & 0.354 & 0.04 \\
\hline $\begin{array}{l}\text { Medium colonies, rela- } \\
\text { tive to mature colonies }\end{array}$ & 63.2 & 0.150 & 0.001 \\
\hline $\begin{array}{l}\text { Mature colonies } \\
(\mathrm{N}=16)\end{array}$ & 29.2 & 0.483 & 0.422 \\
\hline
\end{tabular}

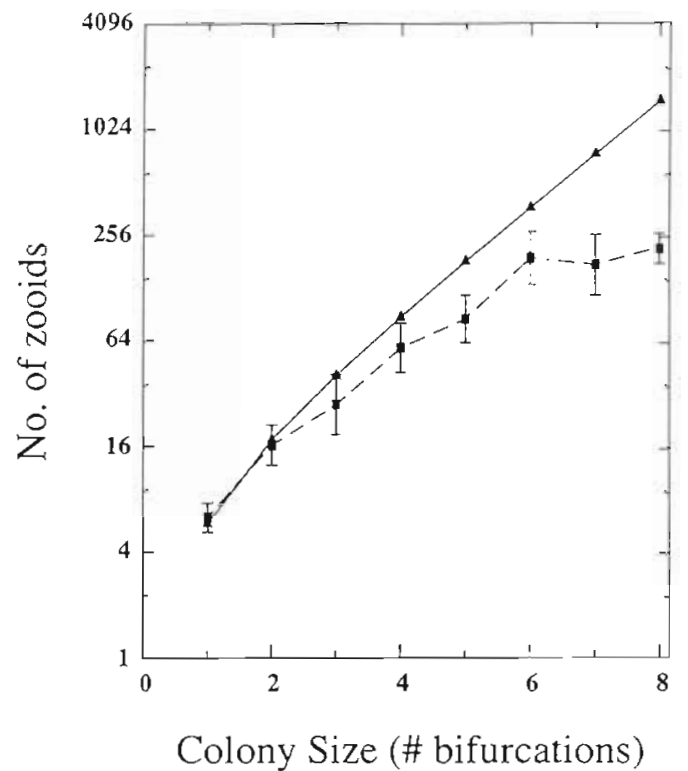

Fig. 2. Bugula neritina. Morphology of colonies at Catalina Island. Number of zooids as a function of number of times colony has bifurcated. (1) Expected values trom completely symmetrical colonies. (ロ) Observed values, with standard deviations where relevant. Sample sizes were, for each size class: 0,$8 ; 1,17 ; 2,26 ; 3,17 ; 4,12 ; 5,9 ; 6,71 ;>6,16$

fewer zooids between successive branch points than in Florida (mean of all measurements $=5.8$ zooids, $\mathrm{SD}=$ $1.85, \mathrm{CV}=31.8 \%, \mathrm{n}=1405$ branches measured; $\mathrm{cf}$. Keough \& Chernoff 1987), but the number of zoolds between branch points was independent of colony size and position within the colony (Table 2). There was no significant variation in morphology among colonies of different sizes; colony size never explained more than $8 \%$ of the variation in the number of zooid pairs, and most of the variation occurred among branches within individual colonies (Table 2). The deviation from the number of zooids expected from a perfectly symmetrical colony increased with colony size (Fig. 2), because branches were frequently broken in larger colonies, and the growing pattern magnifies the effect of such asymmetries.

Only the largest colonies had embryos; no embryos were found in colonies with fewer than 13 bifurcations (Fig. 3). Beyond that size, the proportion of colonies in reproductive condition increased dramatically (Fig. 3) and almost all large colonies had embryos.

\section{Settlement experiments}

The dominant effect on larval swimming time was the presence of settlement cues, with little variation among larvae from different parents or at different temperatures. In the absence of settlement cues, most 
Table 2. Bugula neritina. Morphological variation within bryozoan colonies: analysis of the number of zooid pairs between branch points of colonies. For each level of the colony, the analysis was an unbalanced nested analysis of variance. The table shows $F$ ratios, mean squares, and variance component analysis, ns: $p>0.05 ; \cdot 0.05>p>0.01 ; \cdots p<0.01$

\begin{tabular}{|c|c|c|c|c|c|c|c|}
\hline \multirow[t]{2}{*}{ Variable } & \multicolumn{7}{|c|}{ Bifurcation level ${ }^{a}$} \\
\hline & 1 & 2 & 3 & 4 & 5 & 6 & $>6$ \\
\hline \multicolumn{8}{|l|}{ Mean squares } \\
\hline Colony size & 1.6 & 2.3 & 9.9 & 5.0 & 38.6 & 10.3 & 8.4 \\
\hline Colonies within sizes & 2.7 & 2.6 & 6.8 & 14.0 & 37.7 & 29.3 & 3.5 \\
\hline Branches within colonies & 1.1 & 1.4 & 2.2 & 2.2 & 2.1 & 2.1 & 1.1 \\
\hline \multicolumn{8}{|l|}{ Degrees of freedom } \\
\hline Colony sizes & 6 & 5 & 4 & 3 & 2 & 1 & 1 \\
\hline Colonies within sizes & 81 & 57 & 40 & 29 & 21 & 15 & 15 \\
\hline Branches within colonies & 76 & 145 & 183 & 219 & 154 & 128 & 109 \\
\hline \multicolumn{8}{|l|}{ F-statistics } \\
\hline Colony sizes & $0.5 \mathrm{~ns}$ & $0.7 \mathrm{~ns}$ & $1.3 \mathrm{~ns}$ & $0.3 \mathrm{~ns}$ & $0.8 \mathrm{~ns}$ & $0.4 \mathrm{~ns}$ & $2.5 \mathrm{~ns}$ \\
\hline Colonies within sizes & $2.6^{*}$ & $1.9^{\cdots}$ & $3.1^{\cdots}$ & $6.2^{\cdots}$ & $18.2 \cdots$ & $13.7^{\cdots}$ & $3.3^{*}$ \\
\hline \multicolumn{8}{|l|}{ Variance components } \\
\hline Colony sizes & 0.0 & 0.0 & 1.8 & 0.0 & 0.0 & 0.0 & 8.1 \\
\hline Colonies within sizes & 21.5 & 21.8 & 29.5 & 43.4 & 72.3 & 64.4 & 22.8 \\
\hline Branches within colonies & 80.0 & 79.3 & 68.7 & 61.8 & 30.0 & 42.3 & 69.1 \\
\hline
\end{tabular}

Bugula neritina larvae swam for at least $12 \mathrm{~h}$ and ca $15 \%$ swam for more than $24 \mathrm{~h}$. When suitable settlement cues were provided, $50 \%$ of larvae settled within $2 \mathrm{~h}$ (Fig. 4). There was slight, but non-significant, variation in swimming time among colonies (Table 3 ). There was a slight effect of temperature, but this effect

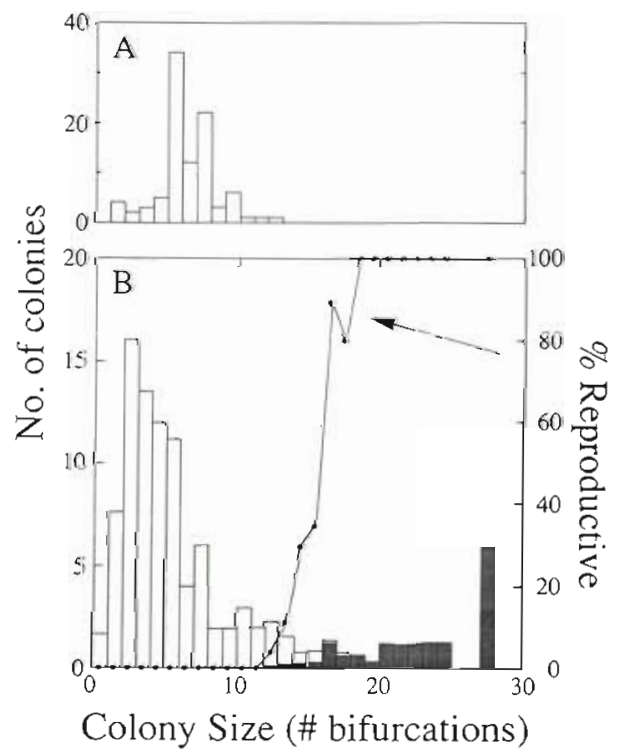

Fig. 3. Bugula neritina. Size-frequency distribution and reproductive state of colonies at Intake Pipes. (A) Size-frequency distributions of juveniles $18 \mathrm{wk}$ after settlement. Data were pooled across grids and canopy treatments. (B) Size-frequencies of naturally-occurring colonies, with shaded sections denoting colonies with embryos. (•) Percentage of colonies of a given size that contained embryos varied with colony (Table 3 ). In this experiment there was no hint of variation among colonies (colonies $x$ time, $G=0.03, \mathrm{df}=1, \mathrm{p}>0.5)$. Most variation in time to settlement occurred among sibling larvae, rather than among temperatures or parental colonies, and by far the strongest effect was that of settlement cues.

\section{Interactions between adults and juveniles}

There was no strong, consistent effect of adult canopies on growth or survival of juveniles. The presence of adults did not affect juvenile mortality during

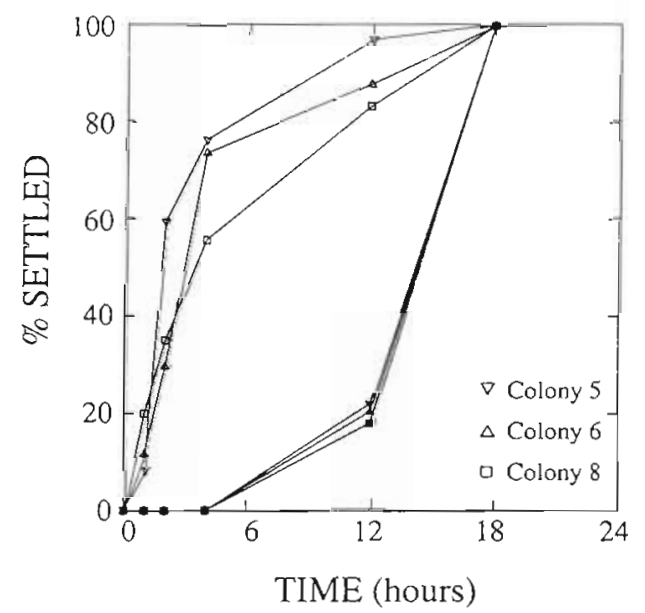

Fig. 4. Bugula neritina. Distribution of settlement times with (open symbols) and without (filled symbols) settlement substrata 
the first month after settlement (Tables 4 and 5). However, mortality of newly-metamorphosed juveniles did vary spatially (Table 4), with juveniles having significantly higher mortality on one grid (No. 3) than on the other two (Table 6). This pattern was maintained through the 18th wk after settlement, after which time there were only 2 juveniles on the third grid (Table 3). Both of these juveniles recruited during the experiment, since they occurred on a tile that had no juveniles after 1 mo. Survivorship was heterogeneous among grids after $18 \mathrm{wk}$ (cumulative survivorship by grid, $\mathrm{G}=$ $41.1, \mathrm{df}=2, \mathrm{p}<0.001$ ), although there was still no significant effect of canopy (survivorship by canopy, G $=1.66, \mathrm{df}=1, \mathrm{p}>0.10 ; 3$-way interaction, survivorship by grid by canopy, $\mathrm{G}=0.94, \mathrm{df}=2, \mathrm{p}>0.5$ ).

Adult canopies also disappeared during the experiment, with the rate of loss varying among grids. Most of the adult canopies were lost from the third grid during the first month, and none remained after $18 \mathrm{wk}$. On the second grid, canopy survivorship was high during the first month, but fell subsequently, while on the first grid, most canopies survived and grew for the duration of the experiment.

The effects of the adult canopy on juvenile growth were more complex (Fig. 5) and varied among grids during the first month after settlement. Most colonies were small ( $<4$ bifurcations; Fig. 5) and symmetrical. Adult canopies had, on each grid, positive, negative, and no effect on juvenile growth. Juveniles in the no canopy treatment showed less heterogeneity in sizes between the grids than juveniles beneath canopies

Table 3. Bugula neritina. Variation in swimming time of bryozoan larvae. The table shows the results of log-likelihood-ratio analysis of the time to settlement of bryozoan larvae. The experiments compared the distribution of swimming times ('Swimming') among larvae from 2 parent colonies ('Parent'). In the first experiment, the third factor was the presence or absence of settlement cues ('Cues'), and in the second experiment, the temperature of the larvae. In each case, the analysis was stepwise deletion of terms from a saturated log-linear model (Bishop et al. 1975), and the G-statistic shown is a goodness-of-fit statistic representing the effect of removing only the term in question from the next most complex model

\begin{tabular}{|c|c|c|c|}
\hline Source of variation & $\mathrm{df}$ & G & $\mathrm{p}$ \\
\hline \multicolumn{4}{|l|}{ Expt 1} \\
\hline $\begin{array}{c}\text { Cues } \times \text { Parents } \\
\times \text { Swimming }\end{array}$ & 8 & 1.7 & 0.50 \\
\hline Cues $\times$ Swimming & 4 & 110.1 & 0.001 \\
\hline Parents $\times$ Swimming & 8 & 14.6 & 0.10 \\
\hline \multicolumn{4}{|l|}{ Expt 2} \\
\hline $\begin{array}{l}\text { Parents } \times \text { Temp } \\
\times \text { Swimming }\end{array}$ & 2 & 5.99 & $0.10-0.05$ \\
\hline Temp $\times$ Swimming & 2 & 2.85 & 0.1 \\
\hline Parents $\times$ Swimming & 1 & 0.03 & 0.5 \\
\hline
\end{tabular}

Table 4. Bugula neritina. Analysis of juvenile growth and mortality on 3 grids in the presence and absence of a canopy of adults. In each case, the analysis was stepwise deletion of terms from a saturated log-linear model (Bishop et al. 1975), and the G-statistic shown is a goodness-of-fit statistic representing the effect of removing only the term in question from the next most complex model. ns: $p>0.05 ; \cdot 0.05>p>0.01$

$$
\cdots 0.01>p>0.001 ; \cdots p<0.001
$$

\begin{tabular}{|lccccc|}
\hline \multirow{2}{*}{ Interaction } & \multicolumn{3}{c}{ Mortality } & \multicolumn{2}{c|}{ Growth } \\
& df & G & df & $G$ \\
\hline Grids $\times$ Canopy & 2 & $21.1 \cdots$ & 2 & $1.8 \mathrm{~ns}$ \\
Grids $\times$ Size/Mortality & 2 & $45.1 \cdots$ & 4 & $12.8^{*}$ \\
Canopy $\times$ Size/Mortality & 1 & $0.8 \mathrm{~ns}$ & 2 & $0.7 \mathrm{~ns}$ \\
Grid $\times$ Canopy $\times$ Size & 2 & $3.3 \mathrm{~ns}$ & 4 & $15.2^{\cdots}$ \\
\hline
\end{tabular}

Table 5. Bugula neritina. Pairwise comparisons of mortality and growth between grids and between canopy treatments. The analyses in each case were log-likelihood ratio goodnessof-fit tests, based on subsets of the data analysed in Table 4 . $\cdot p<0.05 ; \cdots p<0.01 ; n s: p>0.05$

\begin{tabular}{|lcc|}
\hline Comparison & df & $\mathrm{G}$ \\
\cline { 2 - 3 } $\begin{array}{l}\text { Mortality } \\
\text { Grid 1 vs Grid 2 }\end{array}$ & 1 & $1.9 \mathrm{~ns}$ \\
Growth rate & & \\
Canopy vs no-canopy & & \\
Grid 1 & 2 & $0.4 \mathrm{~ns}$ \\
Grid 2 & 2 & $7.2^{\circ}$ \\
Grid 3 & 2 & $8.9^{\circ}$ \\
No canopy only (all grids) & 4 & $8.0 \mathrm{~ns}$ \\
Canopy only (all grids) & 4 & $24.2^{\circ}$ \\
Canopy - Grid 1 vs 2 & 2 & $11.6^{\circ}$ \\
$\quad$ - Grid 1 vs 3 & 2 & 11.2 \\
$\quad-$ Grid 2 vs 3 & 2 & $14.4^{*}$ \\
\hline
\end{tabular}

Table 6. Bugula neritina. Number of juveniles in the canopy experiment. The table shows the number of juveniles in each grid and canopy combination at the beginning of the experiment and at 4 and $18 \mathrm{wk}$ later. The table also shows the number of juveniles that could be identified unambiguously as having recruited after the start of the experiment. - , + without and with adult canopy, respectively

\begin{tabular}{|lrrrrrrrr|} 
& Grid 1 & & \multicolumn{2}{c}{ Grid 2 } & \multicolumn{2}{c|}{ Grid 3 } \\
& - & + & - & + & - & + \\
\hline Total juveniles & & & & & & \\
Start of experiment & 80 & 58 & 85 & 66 & 60 & 59 \\
After 4 wk & 44 & 35 & 42 & 46 & 14 & 19 \\
After 18 wk & 47 & 19 & 16 & 10 & 2 & 0 \\
Recruits & & & & & & \\
After 4 wk & 0 & 0 & 5 & 22 & 0 & 0 \\
After 18 wk & 19 & 3 & 14 & 7 & 2 & 0 \\
\hline
\end{tabular}




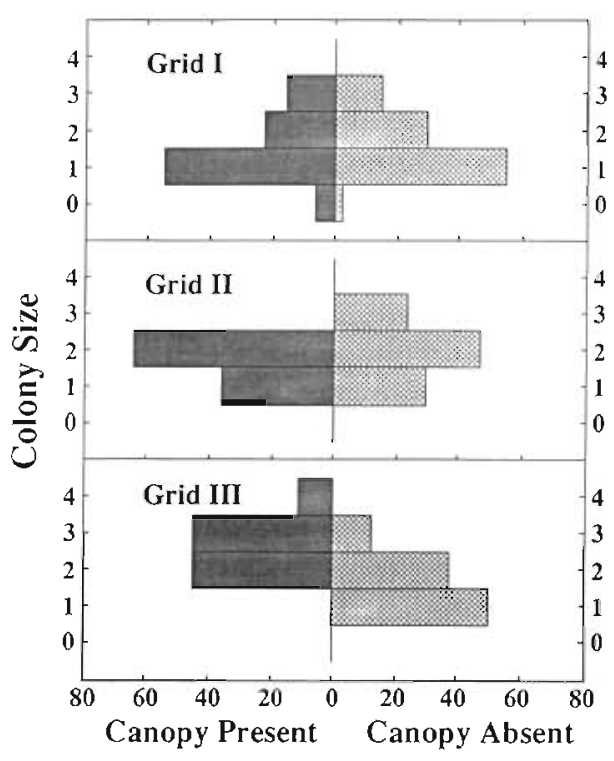

Fig. 5. Bugula neritina. Effects of canopy on growth of juveniles. Size frequency distributions of 1 mo old juveniles are shown for each grid and each canopy treatment

(Fig. 5). By $18 \mathrm{wk}$, there were too few survivors on two of the grids for a powerful test of the size by canopy by grid interaction, and I only compared the size distributions of colonies between canopy and no canopy treatments, pooling across grids. There was no significant difference $(\mathrm{G}=1.34, \mathrm{df}=2, \mathrm{p}>0.5)$, and there was a wide range of sizes among the survivors and recruits.

After $18 \mathrm{wk}$, there had been substantial natural recruitment on two of the grids, making it impossible to identify unambiguously the original transplanted juveniles. Recruitment was almost totally restricted to the 2 grids with higher survivorship. These 2 grids also were those with most of the adult canopies left after 1 mo. Recruitment during the first $4 \mathrm{wk}$ was patchy; there were 36 recruits during this period, all of which were found on the second grid (Table 3). Of these, 21 occurred on a single tile. From the 4 th to the 16 th $w k$, recruitment occurred on 2 grids, although most occurred on the single grid with the most adult canopies intact. The juvenile colonies had grown considerably by that time (Fig. 3 ). Their modal size exceeded the first peak in the size distribution of naturally occurring colonies at Intake Pipes, but fell well short of the size at which reproduction occurs. Extension of this growth rate suggests that it would take a colony at least 1 yr to reach reproductive size, without allowing for loss of tissue through damage.

\section{DISCUSSION}

Bugula neritina colonies in the field are strongly aggregated, and juveniles are generally very close to each other and to large, mature colonies. Proximity to adults appears to have no strong, consistent effects, either positive or negative

What is the cause of the aggregated distribution? The most likely mechanism is restricted dispersal, but possible alternatives are preferential settlement near adults or other juveniles, responses to the same settlement cues as those that induced the adults to settle, and better post-settlement survivorship near adults. I have shown previously that settlement is independent of the presence of established colonies, regardless of the relatedness of larvae and colonies (Keough 1984). Bugula neritina larvae do respond differentially to siblings, settling in a clumped pattern in the laboratory, while settling independently of unrelated larvae (Keough 1984). Settlement behaviour can therefore provide an explanation for the aggregated distribution of juveniles, but not the distribution with respect to adults.

Release of larvae in the field is thought to be synchronized among and within neighbouring colonies (Silén 1972), possibly by an increase in light associated with sunrise; certainly, in the laboratory, most colonies release larvae rapidly when exposed to strong light. The same phenomenon often occurs when colonies are brought to the surface into stronger light. Synchronously-released larvae may disperse under very similar hydrodynamic conditions. Larvae are capable of swimming for up to $2 \mathrm{~d}$, after which time most remain competent to settle and metamorphose. When presented with a substratum suitable for settlement, however, most larvae settle quickly.

Together, these data and the lack of an effect of adults on juvenile survivorship suggest that the proximity of small colonies to mature ones reflects limited dispersal, with their nearest neighbours often being the maternal parent. The most parsimonious explanation for the proximity of small juveniles to each other is a combination of short swimming times, possibly synchronization of release, and iarval recognition of siblings. This explanation and responses to common settlement cues cannot be differentiated, unless the parent colonies and their progeny could be identified unambiguously. This identification has not been done successfully for many benthic organisms (but see Black \& Johnson 1979).

Adults have no consistent effects on juveniles, i.e. there is no obvious selection for or against juveniles settling close to adults. This is consistent with laboratory observations that larvae do not respond strongly to the presence of established colonies, i. e. that there are no great selective advantages or disdvantages associated with this settlement pattern. The similar patterns of disappearance of canopies and juveniles during the experiment suggest that local sites that are poor habitats for adults are poor for juveniles as well. 
Growth of juveniles during the first month was heterogeneous among grids. The effect of adults may be strong, but is highly variable in space.

Are the results from Intake Pipes representative of other sites? The canopy experiment was done at the site with the densest Bugula neritina population, and hence interactions between adults and juveniles should be strongest. It is likely that these interactions are even weaker at Bird Rock and Isthmus Reef, where bryozoan densities are considerably Iower. Only a single adult was used as a neighbour in this experiment, but many adults are more than $10 \mathrm{~cm}$ from a similar-sized neighbour (Fig. 3). The experiment thus represents a common juvenile environment. A woodland is probably a more appropriate metaphor for the adult Bugula colonies than a dense forest.

It is not clear whether the variation among grids represents 'noise' or whether these grids differ consistently; this question could only be answered by repeating the experiment in time. For Bugula stolonifera, Okamura (1985, 1988 has suggested that, at low water velocities, large colonies may reduce the feeding ability of conspecific juveniles, although the size of the effect decreases as flow rate increases. She, and McKinney et al. (1986), have shown that the feeding efficiency of a number of Bugula species may vary with flow regime. If the 3 grids differ slightly in flow regime, these observations provide a plausible mechanism for the results. However, water velocities at Intake Pipes are very low; all sites were on the sheltered side of the island, and this site is deep (>10 m), and beneath a kelp canopy.

Although the interactions between adults and juveniles are inconsistent, there may be strong intraspecific interactions among juveniles (e.g. Buss 1980). The interactions among juveniles have been studied in similar ways at the same study site (Keough unpubl.).

Interactions between large adult organisms and conspecific juveniles have been studied most intensively in temperate and tropical forests. Although many authors have shown strong positive relationships between juvenile survivorship and distance from canopy (Platt 1976, Augspurger 1983), others have failed to find such a relationship (Connell et al, 1984). There appears to be no consistent effect across species (Hubbell 1980, Clark \& Clark 1984, Connell et al. 1984), and Janzen (1975) has shown that the effect may not even be consistent in different parts of the range of a single species.

There are few studies of the interactions between adults and recruits of marine animals. Arborescent species, such as Bugula spp., are common subtidally, and often have restricted larval periods (and, presumably, dispersal) (Thorson 1950, Jackson 1985). On hard substrata almost all sessile organisms are suspension feeders, and adults and juveniles feed from the water column. Many subtidal habitats do not have rapid currents, and the resulting extensive boundary layer effects near the substratum could allow large organisms to affect the flow of food to those organisms that are closer to the substratum, as has been suggested by a number of authors (Reiswig 1974, Buss 1980, Wright et al. 1982). Although no such interaction could be shown in this case, that does not preclude the possibility that such interactions are widespread and important among subtidal benthic organisms.

Acknowledgements. This work was supported by NSF grant OCE-8400404 and the NOAA National Undersea Research Program at Catalina Marine Science Center. I thank Dr A. Muscat and the staff of the Catalina Marine Science Center for their cooperation. Field assistance was provided by $J$. Schmidt, R. Vance, R. Varon, M. Carr, and the tether diving support crew. R. Vance devised the method of manipulating canopies and he, J. Travis, B. Downes, A. Butler, and J. Schmidt, and 3 anonymous reviewers commented on the manuscript. This is Publication 130 from the Catalina Marine Science Center.

\section{LITERATURE CITED}

Augspurger, C. K. (1983). Offspring recruitment around tropical trees: changes in cohort distance with time. Oikos 40 : $189-196$

Ayre, D. J. (1985). Localized adaptation of clones of the sea anemone Actinia tenebrosa. Evolution 39: 1250-1260

Bergquist, P. (1981). Sponges. University of California Press, Berkley, California, USA

Bishop, Y M. M., Feinberg, S. E., Holland, P. W (1975). Discrete multivariate analysis. MIT Press, Cambridge

Black, R., Johnson, M. S., (1979). Asexual viviparity and population genetics of Actinia tenebrosa. Mar. Biol. 53: 27-31

Burton, R. S. (1983). Protein polymorphisms and genetic differentiation of marine invertebrate populations. Mar. Biol. Lett. $4: 193-206$

Buss, L. W. (1980). Bryozoan overgrowth interactions - the interdependence of competition for space and food Nature, Lond. 281: 475-477

Clark, D. A., Clark, D. B., (1984). Spacing dynamics of a tropical rain forest tree: evaluation of the Janzen-Connel] model. Am. Nat. 124: 769-788

Connell, J. H. (1971). On the role of natural enemies in preventing competitive exclusion in some marine animals and in rainforest trees. In: den Boer, P. T. Gradwell, G. R. (eds.) Dynamics of populations. PUDOC, Wageningen, $p$ 298-312

Connell, J. H. (1978). Diversity in tropical rain forests and coral reefs. Science 199: 1302-1310

Connell, J. H., Tracey, J. G., Webb, L. J., (1984). Compensatory recruitment, growth and mortality as factors maintaining rain forest tree diversity. Ecol. Monogr. 54: 141-164

Davis, A. R. (1987). Variation in recruitment of the subtidal colonial ascidian Podoclavella cylindrica (Quoy \& Gaimard): the role of substratum choice and early survival. J. exp. mar. Biol. Ecol. 106: 57-71

Fadlallah, Y H., Pearse, J. S. (1982). Sexual reproduction in solitary corals: overlapping oogenic and brooding cycles and benthic planulas in Balanophyllia elegans. Mar. Biol 71: $223-231$ 
Fowler, N. J., Antonovics, J. (1981). Small scale variability in the demography of transplants of two herbaceous species. Ecology 62: 1450-1457

Gerrodette, T. (1981). Dispersal of the solitary coral Balanophyllia elegans by demersal planular larvae. Ecology 62: 611-619

Harper, J. H. (1977). Population biology of plants. Academic Press, New York

Hopkins, B., Skellam, J. G. (1954). A new method for determining the type of distribution of plant individuals. Ann Bot. Lond. NS 18: 213-227

Hubbell, S. P. (1980). Seed predation and the coexistence of tree species in forests. Oikos 35: 214-229

Jackson, J. B. C. (1985). Distribution and ecology of clonal and aclonal benthic invertebrates. In: Jackson, J. B. C., Buss, L. W., Cook, R. E. (eds.) Population biology and evolution of clonal organisms. Yale University Press, New Haven, p. 297-356

Janzen, D. H. (1970). Herbivores and the number of tree species in tropical forests. Am. Nat. 104: 501-528

Janzen, D. H. (1975). Intra- and interhabitat variations in Guazuma ulmifolia (Sterculiaceae) seed predation by Ambycercus cistellinus (Bruchidae) in Costa Rica. Ecology 56: $1009-1013$

Keough, M. J. (1984). Kin-recognition and the spatial distribution of larvae of the bryozoan Bugula neritina. Evolution 38: $142-147$

Keough, M. J. (1986). The distribution of the bryozoan Bugula neritina on seagrass blades: settlement growth and mortality. Ecology 67: 846-857

Keough, M. J. (1989). Benthic populations: is recruitment limiting or just fashionable? Proc. 6th Int. Coral Reef Symp. (in press)

Keough, M. J., Chernoff, H. (1987). Dispersal and population variation in the bryozoan Bugula neritina. Ecology 68 199-210

Keough, M. J., Downes, B. J. (1982). Recruitment of marine invertebrates: the role of active larval choices and early mortality. Oecologia (Berl.) 54: 348-352

Keough, M. J., Downes, B. J. (1986). Effects of settlement and post-settlement mortality on the distribution of the ascidian Trididemnum opacum. Mar. Ecol. Prog. Ser. 33: 279-285

Levin, L. A. (1984). Life history and dispersal patterns in a dense infaunal polychaete assemblage: community structure and response to disturbance. Ecology 65: 1185-1200

McKinney, F. C., Listokin, M. R. A., Phifer, C. D. (1986). Flow and polypide distribution in the cheilostome bryozoan Bugula and their inference in Archimedes. Lethaia 19: 81-93

Mihm, J. W., Banta, W. C., Loeb, G. I. (1981). Effects of adsorbed organic and primary fouling films on bryozoan settlement. J. exp. Mar. Biol. Ecol. 54: 167-179

This article was presented by Dr P. W. Sammarco, Townsville, Australia
Okamura, B. (1985). The effects of ambient flow velocity, colony size, and upstream colonies on the feeding success of Bryozoa. I. Bugula stolonifera Ryland, an arborescent species. J. exp. mar. Biol. Ecol. 83: 179-193

Okamura, B. (1988). Influence of neighbours on feeding of an epifaunal bryozoan. J. exp. mar. Biol. Ecol. 120: 105-123

Olson, R. R. (1985). The consequences of short-distance larval dispersal in a sessile marine invertebrate. Ecology 66: $30-39$

Platt, W J. (1976). The natural history of a fugitive prairie plant (Mirabilis hirsuta [Pursh] MacM.). Oecologia (Berl.) 22: 399-409

Reiswig, H. M. (1974). Water transport, respiration and energetics of three tropical marine sponges. J. exp. mar. Biol. Ecol. 14: 231-249

Resing, J. M. Best, B. A. (1989). Local recruitment of juveniles observed in a dominant Pacific reef coral. Proc. 6th Int. Coral Reef Symp. (in press)

Scheltema, R. S. (1971). The dispersal of the larvae of shoalwater benthic invertebrate species over long distances by ocean currents. In: Crisp, D. J. (ed.) 4th Eur. Mar. Biol. Symp. Cambridge University Press, London, p. 7-28

Sebens, K. (1983). The larval and juvenile ecology of the temperate octocoral Alcyonium siderium Verrill. I. Substratum selection by benthic larvae. J. exp. mar. Biol. Ecol. 71. $73-89$

Silén, L. (1972). Fertilization in the Bryozoa. Ophelia 10: 27-34

Simberloff, D. S. (1979). Nearest neighbour assessment of spatial configuration of circles rather than points. Ecology 60: 679-685

Thorson, G. (1950). Reproductive and larval ecology of marine bottom invertebrates. Biol. Rev. 25: 1-45

Turkington, R., Harper, J. L. (1979). The growth distribution and neighbour relationships of Trifolium repens in a permanent pasture IV. Fine-scale biotic differentiation. J. Ecol 67: 245-254

Vance, R. R. (1978). A mutualistic interaction between a sessile marine clam and its epibionts. Ecology 59: 679-685

van Duyl, F. C., Bak, R. P. M., Sybesma, J. (1981). The ecology of the tropical compound ascidian Trididemnum solidum. I. Reproductive strategy and larval behaviour. Mar Ecol. Prog. Ser. 6: 35-42

Winston, J. E. (1982). Marine bryozoans (Ectoprocta) of the Indian River area (Florida). Bull. Am. Mus. nat. Hist. 173: 102-176

Wright, R. T., Coffin, R. B., Ersing, C. P., Pearson, D. (1982) Field and laboratory measurements of bivalve filtration of natural marine bacterioplankton. Limnol. Oceanogr. 27 : 91-98

Young, C. M. (1986). Direct observations or field swimming behavior in larvae of the colonial ascidian Ecteinascidia turbinata. Bull. mar. Sci. 39: 279-289

Manuscript first received: February 5, 1989

Revised version accepted: July 20, 1989 